\title{
문화와 발전을 위한 ODA 구상: 국제개발협력의 담론과 정책
}

이태주 (한성대학교 교양학부 문화인류학 교수)

\section{목 차}

I. 최근 국제사회의 $\mathrm{ODA}$ 동향

1. 글로벌 다중위기 이후 국제개발협력의 새로운 담론들

2. 개발협력 정책과 동향

II. 문화 $\mathrm{ODA}$ 의 필요성과 현황

1. 문화 ODA의 가치

2. 국제사회의 문화 ODA에 대한 논의

III. 우리나라 문화 ODA 추진과제

1. 우리나라 문화 ODA 현황

2. 우리나라 문화 ODA 추진과제

\section{I . 최근 국제사회의 ODA 동향}

이 연구에서는 문화와 발전에 관한 공적개발원조(ODA, official development assistance)를 구상하기 위해 최근 국제사회의 ODA 동향과 변화 추이를 담론(discourse)과 정책(policy) 수준에서 분석하고, 문화 $\mathrm{ODA}$ 모델 개발과 적용 가능성에 대한 객관적이고 타당한 근거를 찾아보고자 한다. 특히 Rio+20와 post-MDG 논의의 핵심으로 대두되고 있는 지속가능한 발전(sustainable development)과 포용적 발전(inclusive development), 평화구축(peace building)이라는 세 가지 담론과 정책은 향후 문화와 발전 간 불가분의 상호 관련성을 제시하는 핵심 논의로 볼 수 있기 때문에 이러한 논의를 중심으로 문화 분야 국제개발협력의 향후 과제를 모색하고자 한다.

글로벌 발전 담론에서 지속가능 발전의 3 대 축이 경제, 사회, 환경이라면 4 번째 축은 문화이다. 문화는 모든 개발협력 노력에서 항상 고려해야 하는 조건이고 중요한 가치규범이며 협력의 원칙인 
동시에 모든 개발 노력의 궁극적 목적으로서 주민들에게 삶의 의미와 만족감, 정체성과 행복을 가져다주는 원천이다. 따라서 이 연구에서 '문화 ODA'는 협의의 의미에서 문화 분야에 대한 ODA 사업을 지칭할 뿐 아니라 경제, 사회, 환경과 더불어 지속가능발전을 위한 개발협력의 횡단 주제이고 포용적 발전을 위한 핵심 전략이라고 할 수 있다. 이 연구에서 문화 $\mathrm{ODA}$ 는 포괄적이고 확장된 의미에서 사용되며, 경제, 사회, 기술, 제도, 환경적 변화와 개발 사업이 주민들에게 삶의 의미와 유대감, 정체성을 가져다주는 긍정적 변화가 되도록 문화를 고려하고 문화의 담지자(주체)들에 의해 설계되어야 한다는 협력의 원칙이다. 그러므로 문화 ODA는 개발주권을 강화하는 원칙이며, 올바른 사회변화와 지속가능 발전을 실천하는 근본 원리이다.

\section{1. 글로벌 다중위기 이후 국제개발협력의 새로운 담론들}

\section{(1) 글로벌 개발지형과 담론 변화}

2008년 글로벌 금융위기 이후 세계는 식량, 에너지, 환경을 포함한 복합적 다중 위기(multiple crisis)에 직면하게 되었으며 그 결과 전 세계적으로 글로벌 공공재(global public goods)에 대한 투자가 약화되고 특히 급격한 외부 변화에 적응하기 취약한 국가들인 최빈국과 저개발국의 '개발위기' 가 심화되고 있다. 글로벌 금융위기 이후 식량과 에너지의 가격 변동성이 커지고 이는 최빈국과 개발도상국의 농민과 취약계층의 생계를 위협하게 됨으로써 인간안보와 식량안보에 중대 위기를 초래하게 되었다. 결국 글로벌 경제위기의 최대, 최종 피해자는 10 억의 빈곤층 $(\mathrm{BOP}$, base of pyramid)이라 할 수 있다. 이러한 위기 상황에서 글로벌 금융위기 이후 지속적 경제성장과 회복을 위한 G20 국가들의 역할이 강조되었으며, BRICs를 포함한 신흥 경제국들이 세계 경제와 정치 및 개발협력에서 차지하는 영향력이 급속히 증대되었다. 특히 전통적인 공여국과 수원국이라는 이분법적인 식민지 권력구도와 구분이 사라지고 '개발협력 제공자'(development cooperation provider)와 '파트너 국가'(partner country)라는 용어를 사용하게 되는 등 글로벌 원조체제(global aid architecture)의 근본적 역학 변동이 진행되었으며, 남남협력(south-south cooperation)과 개발원조위원회 비회원국(non-DAC)의 영향력도 점차 증대되고 있다.

한편, 경제위기의 심화로 인하여 시장자유화와 정부의 규제 철폐를 주창하는 신자유주의 개발 이념에 대한 비판적 논의가 세계적으로 확산되었으며, 개발도상국들에서도 세계은행을 중심으로 확산되었던 '워싱톤 컨센서스'가 급격히 약화되고 이를 대체할 다양한 개발정책과 이념이 모색되고 있다. ${ }^{1)}$ 특히 개발도상국 발전 경로의 역사적, 지정학적 다양성과 특수성을 인정해야 한다는 주장이 점차 일반화되고 있으며 하나의 동일한 처방(one-size-fits-all) 방식을 경계하는 논의가 주류화되고 있다. 주목할 것은 금융위기 이후 정부 재정을 보완하고 대체할 많은 다양한 개발주체들이 등장하고 있으며 특히 민간부문(private sector)의 참여가 G20로부터 OECD와 UN에서도 강조되고 있다는 것이다. 민간부문은 무역과 투자를 통한 지속적 경제성장의 엔진일 뿐 아니라 일자리를

1) Stefan Halper(2010), The Beijing Consensus, Basic Books: New York. 
창출하고 인적자원을 개발하며 인프라를 구축하는데 있어서도 효과적이고 효율적인 개발주체로서 그 중요성을 인정받고 있다. 따라서 개발협력에서도 민간부문과의 효과적인 파트너십(public-private partnership, PPP)이 매우 중요하게 인식되고 있으며 빈곤과 분쟁, 질병 등 근본적인 개발문제를 해결하기 위한 글로벌 개발 파트너십을 구축하는데 있어서도 정부와 민간, 시민사회의 공동 노력이 중요해지고 있다.

또한 전통적인 주요 공여국들은 재정위기로 인하여 최근 수 년 동안 $\mathrm{ODA}$ 자금을 지속적으로 축소하는 경향이 나타나고 있으며, 특히 그리스, 스페인, 이탈리아, 네덜란드, 일본 등은 2008년 이후 지속 감소 경향을 보이고 있다. 2012년 기준으로 개발원조위원회(DAC)의 ODA 통계를 보면 한국, 호주, 룩셈부르크, 오스트리아, 아이슬란드, 스위스, 캐나다, 뉴질랜드, 노르웨이를 제외한 주요 DAC 공여국들(미국, 영국, 독일, 프랑스, 일본, 네덜란드, 스웨덴, 이탈리아, 스페인, 벨기에, 덴마크, 포르투갈, 그리스, 체코, 핀란드 등)의 ODA가 실질적으로 감소하였다. 특히 양자간 원조가 $5 \%$ 감소한 것에 비하여 다자간 원조는 $9 \%$ 나 감소하였으며, DAC 국가의 평균 $\mathrm{GNI}$ 대비 ODA 비율도 2011 년 대비 $0.31 \%$ 에서 $0.29 \%$ 로 감소하였다.

\section{(2) Rio+20와 지속가능발전}

1992년 리우 환경개발회의 이후 20년 만인 2012년 6월, 유엔지속가능발전회의(United Nations Conference on Sustainable Development, UNCSD)가 브라질 리우데자네이루에서 다시 개최되었다. 이 회의에서 채택된 정치 선언문인 '우리가 원하는 미래'(The Future We Want) 에는 인류의 공동비전과 지속가능발전, 빈곤퇴치, 그리고 녹색경제를 위한 정치적 약속과 제도 및 체제구축, 행동계획과 이행수단을 제시하고 있다. 리우 +20 회의에서는 post-MDG를 위한 지속가능개발목표(SDGs, Sustainable Development Goals)를 설정하는데 합의한 것이 가장 큰 성과라고 할 수 있으며, post-MDG와 SDG가 통합되어 일관성 있게 추진되어야 함을 강조하고 있다. 이 회의에서 $\mathrm{SDG}$ 는 지속가능발전의 세 축인 경제, 사회, 환경을 잘 통합하여 연계할 수 있도록 해야 함을 강조하였으며, SDG는 행동지향적이고, 간결하고, 소통이 용이하고, 목표 수가 많지 않고, 각국의 현실을 고려하되 모든 국가에 적용 가능한 것으로 정하는 기본원칙에 합의하였다. 또한 리우 +20 회의에서는 지속가능발전을 추구하기 위해 기존의 경제중심 발전지표인 국내총생산 (GDP, gross domestic product) 지표를 보완하여 진보를 폭넓게 측정할 수 있는 지표를 개발하기로 합의한 것도 주목할 만하다. 이미 다양한 방식으로 삶의 질과 발전을 측정하는 지표들이 개발되고 있음을 주목할 필요가 있는데, 부탄의 국민총행복지수(GNH, Gross National Happiness)나 OECD 가 개발한 웰빙 지수2), 프랑스 정부가 아마르티야 센, 스티글리츠, 장폴 피투시에 요청하여 개발한 삶의 질 지수 ${ }^{3)}$ 가 대표적인 사례이다.

2) OECD(2011), How's Life?: Measuring Well-being, OECD Publishing.

3) Stiglitz, J.E., Sen, A.\& Fitoussi,J-P.(2010), Mismeasuring Our Lives: Why GDP Doesn't Add Up, The New Press. 
1972년 스톡홀름 유엔인간환경회의에서 당시 인도 수상이었던 인디라 간디가 말한 바와 같이 “빈곤이야말로 최악의 환경오염”이고, 빈곤퇴치는 오늘날 인류가 당면한 가장 중요한 도전이고 지속가능발전의 필수불가결한 조건임을 리우회의에서도 확인하였다. 리우 +20 회의는 지속가능발전을 위한 26 개의 우선순위 분야 중에서 특히 '지속가능한 소비 및 생산'에 관한 10년 계획을 채택함으로써 지속가능발전이 생산과 소비를 포함한 생활양식과 문화의 변화를 포함하는 것임을 확인하였다는 점을 강조할 필요가 있다. 즉, 경제와 사회, 환경은 불가분의 관계에 있고 지속가능 발전은 생활양식과 의식을 포함하는 문화의 변화 없이는 달성이 불가능 하다는 것을 확인시켜 준 것이다. 참고로 지속가능발전의 26 개 우선분야는 빈곤퇴치, 식량안보와 지속가능한 농업, 물과 위생, 에너지, 지속가능관광, 지속가능교통, 지속가능도시와 거주, 건강과 인구, 모든 이를 위한 고용과 일자리, 해양과 바다, 군소도서국, 최빈국, 내륙개발도상국, 아프리카, 지역적 노력, 재난위험 감소, 기후변화, 산림, 생물다양성, 사막화와 토지황폐화 및 가뭄, 산, 화학물질과 폐기물, 지속가능한 소비와 생산, 채굴, 교육, 성 평등과 여성 권한강화 등이다. 이러한 우선분야들은 모두 문화와 발전 간의 불가분의 관계에서 고려해야 하는 것들이지만, 특히 '지속가능발전의 4 번째 축으로서 문화'를 고려한다면 지속가능관광, 도시와 주거, 건강, 생물다양성, 지속가능한 소비와 생산, 교육, 성 평등 등이 문화와 직접적으로 관련되는 분야이다.

리우 +20 에서 확인할 수 있듯이 결국 지속가능발전 담론은 경제와 환경, 사회를 넘어서 인류 공동의 통합 이념과 비전으로 확장되고 있으며, 앞으로는 이들 세 축을 연계하고 통합하는 근저의 원리로서 다양한 인간의 삶의 방식, 생활양식, 의식과 이념을 포함하는 문화를 적절히 고려하지 않고서는 지속가능발전 논의를 발전시킬 수 없게 되었다. 때문에 문화는 지속가능발전의 4 번째 축이거나 적어도 세 개의 축을 연결하는 근저의 원리가 되어야 한다.

\section{(3) Post-MDG 논의와 새로운 개발 담론4)}

2015년 목표 달성 시한을 2년여 앞두고 있는 현재 8개의 글로벌 목표로 이루어진 새천년개발목표 $(\mathrm{MDG})$ 는 달성이 어려울 것으로 예상된다. 그럼에도 불구하고 $\mathrm{MDG}$ 는 인류 역사상 최고의 구체적인 공동 목표로서 지난 10 여 년 동안 실질적으로 영향력 있는 국제개발 규범으로 작동하였으며 빈곤퇴치와 보편적 교육, 질병감소 등에서 많은 성과를 거두는데 기여하였다고 평가된다. 특히 MDG 는 기존의 경제개발 중심의 개발 패러다임을 사회개발과 인간개발 중심으로 전환하는데 결정적인 영향력을 미쳤고, 냉전시대의 종말로 인한 국제개발협력 노력의 퇴조와 개발의 위기를 타개하는데 기여하였다. MDG라는 최소한의 인권기준과 글로벌 목표를 달성하기 위한 전 지구적 노력을 재생시켰으며 빈곤퇴치를 개발협력의 최고 목표로 설정하는데 기여하였다.

4) UN(2013). A New Global Partnership: Eradicate Poverty and Transform Economies Through Sustainable Development, The Report of the High-level Panel of Eminent Persons on the Post-2015 Development Agenda, United Nations., 임소진(2013), Post-2015 개발 프레임워크와 UN 고위급패널보고서, 정책과 이슈 10호, KOICA 
그러나 주지하듯이 MDG에서는 빈곤퇴치 이외에 인류가 당면한 주요 문제들인 기후변화, 불평등, 분쟁과 평화정착, 인권, 양성평등과 문화 다양성의 문제를 간과하였으며, 지구촌의 극빈층과 빈곤국에만 적용되는 최소한의 개발목표(minimum development goals)로 작동했다는 한계를 내포하고 있다. 또한 $\mathrm{MDG}$ 는 최빈국과 개발도상국에만 적용되는 목표로서 선진 공여국들이 개도국에 $\mathrm{MDG}$ 달성을 강요한 측면이 있으며, 선진국을 포함한 인류가 공동으로 해결해야 하는 지속가능한 발전과 생물 종 문화다양성 보호 및 평화와 인권 등 공동의 책무와 이행과제를 소홀히 했다는 비판도 존재하고 있다. MDG에 대한 이러한 평가와 비판에 근거하여 현재 다양한 관점에서 Post-MDG에 대한 논의가 진행 중이며, 이미 2015년 이후 인류가 해결해야 하는 새로운 글로벌 목표를 설정하기 위한 '유엔 고위급패널 보고서'가 유엔 사무총장에게 제출되었고 이를 토대로 향후 협상을 위한 반기문 사무총장의 보고서가 제출되었다. ${ }^{5)}$ 이로서 향후 유엔을 중심으로 최종 Post-MDG 아젠다를 확정하기 위한 다양한 협상과정이 전개될 예정이다.

향후 Post-MDG를 확정하기 위한 협상과정에서 기본문서가 될 '유엔 고위급 패널 보고서'에서는 5 개의 핵심과제를 설정하였는데, 이는 모두를 위한 빈곤퇴치(leave no one behind), 지속가능한 발전의 중심화, 일자리 창출과 포용적 성장을 위한 경제구조 변화, 평화와 효과적이고 투명하며 책임 있는 공공제도 구축, 새로운 글로벌 파트너십 구축이 그것이다. 이 보고서에는 12 개의 목표와 54 개 항목의 세부목표를 예시하고 있는데 이는 MDG의 구체적 지표설정 방식을 계승한 것으로 정해진 기한 내에 구체적인 이행 목표를 달성하도록 하는 방식이다. 즉 구체적이고(specific), 측정가능하며 (measurable), 달성 가능하고(achievable), 적실성이 있으며(relevant), 시한이 정해진(timebound) SMART 원칙을 적용하였다. 이 보고서에서 제시하고 있는 12 개의 글로벌 목표는 빈곤퇴치, 소녀 및 여성 역량강화와 양성평등, 양질의 교육과 평생학습, 건강한 삶, 식량안보와 영양개선, 물과 위생에 대한 보편적 접근, 지속가능한 에너지 확보, 일자리 창출과 지속가능한 생계 및 공평한 성장, 천연자원 자산의 지속가능한 관리, 굿 거버넌스와 효과적 제도 보장, 안정적이고 평화로운 사회 보장, 글로벌 차원의 가능한 환경 조성 및 장기적 재원 촉진이다.

Post-2015 개발의제를 위한 유엔 사무총장 보고서(UN, 2013)는 MDG에서 고려되지 못했던 불평등과 청년고용, 분쟁, 인구, 환경문제를 포함시키고 있으며 2030년까지 세계의 모든 인류가 품위 있는 삶의 권리를 실현시킬 수 있도록 하는 담대한 비전을 포함하고 있다. 이 보고서에서는 지속가능한 개발의제 실현을 위해 4개의 빌딩 블럭을 제시하고 있는데, 이는 1) 유엔헌장과 세계인권선언 및 새천년선언에 명시된 인권과 보편가치에 입각한 미래에 대한 원대한 비전 2) 의제의 우선순위를 실현할 수 있는 일련의 간결한 목적과 목표 3) 이행 수단을 동원할 수 있는 글로벌 개발 파트너십 4) 진전 상황을 추적할 수 있는 참여적 모니터링과 모든 이해관계자들의 상호책무성 메커니즘이 그것이다. 특히 이 보고서는 post-2015 개발의제에 포함시켜야 하는 15 개의 목표를 제시하고 있는데 이는 1) 모든 종류의 빈곤퇴치 2) 배제와 불평등 해소 3) 여성과 소녀의 권한강화 4)

5) UN(2013). A Life of Dignity for All: Accelerating Progress towards the Millenium Development Goals and Advancing the United Nations Development Agenda Beyond 2015. General Assembly A/68/202. New York, UN. 
양질의 교육과 평생교육 제공 5) 보건증진 6) 기후변화 대처 7) 환경문제 대처 8) 포용적이고 지속가능한 성장과 좋은 일자리 촉진 9) 기아와 영양실조 종식 10) 인구학적 도전 대처 11) 이민자의 긍정적 기여 증진 12) 도시화 문제 대처 13) 법치와 건전 제도에 입각한 평화와 효과적 거버넌스 구축 14) 새로운 글로벌 파트너십 강화 15) 국제개발협력 프레임워크 강화이다. 이 중에서 특히 배제와 불평등 해소, 평생교육, 환경과 기후변화 문제, 좋은 일자리, 이민자의 긍정적 기여, 도시화 문제, 평화구축과 효과적 거버넌스 등은 문화와 발전 의제와 관련하여 주목할 만한 향후 개발의제라고 할 수 있다.

이상에서 살펴 본 바와 같이 Post-2015 아젠다 논의에서도 지속가능발전이 핵심 개념으로 등장하고 있으며 향후 Post-MDG와 SDG를 통합하는 원칙에 합의하여 협상이 진행될 것인 바, 빈곤퇴치라는 글로벌 개발목표가 지속가능 발전으로 이동할 것은 명백해 지고 있다. 그러나 문화와 발전 논의에서 가장 중요한 문화다양성과 생물 종 다양성의 보호, 인권에 기반한 개발과 문화권 보장, 소수민족과 소수자의 문화권 등과 같은 이슈들은 아직 전혀 반영되고 있지 못하고 있다.

\section{2. 개발협력 정책과 동향}

\section{(1) 개발효과성과 개발정책 일관성}

1990년대부터 본격적으로 제기되어 왔고 2005년 파리선언을 통해 국제개발협력의 주요 정책과 이행지표로 구체화되었던 원조효과성(aid effectiveness)은 제4차 부산 원조효과성고위급회의 (HLF-4)에서 보다 폭넓은 개발효과성(development effectiveness) 정책으로 진전되었다. 이는 원조가 개발을 달성하는데 중요한 촉매 역할을 하지만 다른 효과적인 정책 수단들과 일관성을 갖고 관리되어야 비로소 효과를 거둘 수 있다는 인식이 확산된 결과이다. 즉, 개발은 무역, 투자, 이민, 농업, ICT, 성 평등, 환경정책 등과 연계되어야 효과가 나타나고 공여국과 파트너국가 모두 개발을 위한 정책일관성(policy for development, PCD)을 충분히 고려해야 한다는 것이다.

'원조효과성에서 개발효과성으로'의 논의 진전은 원조가 개발목표를 달성하는 촉매제에 불과하며 원조의 역할이 과장되어서는 곤란하다는 비판적 인식도 작용한 결과이다. 문제는 개발의 목표와 내용이 무엇인가를 규정하는 것인데 개발은 단순한 경제적, 양적 성장만을 의미하는 것이 아니라 인간의 삶의 질과 공동체의 제반 조건을 향상시키는 것을 의미하며, 주민들의 민주적인 참여와 권리 및 역량을 확대하는 것이어야 한다는 점을 명확히 하게 되었다. 때문에 개발협력 노력으로 개발효과성을 높이기 위해서는 무엇보다도 개발이 인권에 기반하여야 하고(right-based approach, $\mathrm{RBA}$ ) 지속가능한 발전에 기여하는 것이어야 하며, 보다 포용적이고 균형적이어야 한다. 또한 개발은 빈곤과 마찬가지로 다차원적이고 복잡하게 상호 연결된 것이어서 물질과 정신, 기술과 규범체계가 동시에 고려되어야 부정적 효과를 최소화하고 갈등과 분쟁, 혼란을 줄이고 개발 목표를 달성할 수 있다는 것을 확인하는 계기가 되었다. 특히 개발은 주민에 의한, 주민을 위한, 주민을 중심으로 수행되어야 한다는 '인간중심의 접근' (people-centered development)이 중요하다는 것도 확인하는 계기가 되었다. 


\section{(2) 오너십과 다양한 발전 경로}

외부에 의한 계획적이고 의도적인 개입이라고 할 수 있는 개발협력은 그것이 아무리 선한 의도라고 할지라도 결과적으로 개발의 주체인 주민들을 더욱 주변화하고 무력하게 하며 빈곤의 덫에서 빠져 나오지 못하게 하는 원조 의존성과 '원조 종속'(aid dependency) 문제를 야기하기 쉽다. 외부에 의한 강요나 이식, 무차별적인 개입은 궁극적으로 개발이 아닌 영구적인 빈곤과 종속, 주변화를 초래하기 때문에 개발주권(ownership)6)은 개발협력 정책과 원칙 중에서도 가장 중요한 것이다. 개발주권이 개발도상국 국민과 주민들 스스로에 있기 때문에 공여국과 외부의 개발협력 제공자들은 개발주권의 소유자이고 개발의 주체인 주민들의 욕구와 필요, 파트너 국가의 개발정책과 개발방식을 존중하고 이들의 다양한 역사와 문화, 지정학적 조건을 고려한 다양한 발전의 경로를 인정해야 하며 신자유주의와 공여국의 일방적인 발전 경험을 이식하거나 전수하는 것은 바람직하지 못한 결과를 초래할 수 있다. 1980년대에 아프리카에서 행해졌던 세계은행의 구조조정 원조(SAP, structural adjustment program)가 아프리카 경제를 파탄시키고 오히려 빈곤을 악화시킨 결과를 초래한 대표적 사례 때문에 개발주권 논의가 본격화되었으며 파리선언의 제 1 원칙도 오너십이다. 그러나 현재까지도 대부분의 공여국들은 원조의 조건으로 많은 정책들을 강요하는 원조(conditionality) 를 하고 있으며, 대다수의 기술협력 프로그램도 공여국의 기술과 기자재, 노하우를 활용하는 것을 조건으로 하는 조건부 원조(tied aid)인 경우가 많다.

\section{(3) 민관협력과 혁신적 개발재원}

글로벌 문제를 해결하기 위한 개발재원의 부족이 점차 심화되면서 정부의 재정에만 의존하는 형태의 기존 개발협력 방식을 벗어나 다양한 혁신적 개발재원 동원에 대한 논의가 지난 10 여 년 동안 진행되어 왔으며 개발재원에 대한 몬테레이 회의에서 합의된 몬테레이 컨센서스가가 대표적인 성과이다. 특히 새로운 개발재원으로서 민간부문의 자금을 적극 동원하고 ODA 공적자금과 연계하여 실질적인 개발성과를 거둘 수 있는 사례와 주장이 확산되면서 최근 남남협력과 더불어 민관협력 (PPP)이 매우 강조되고 있다. 기업들도 글로벌 사회공헌과 기업의 사회적 책임(Corporate Social Responsibility, CSR)이 자선을 넘어 기업의 핵심 미래전략으로 부상하면서 개발도상국과 지구촌의 빈곤층 주민들을 목표로 하는 BOP 비즈니스와 임팩트 투자(impact investment)를 확산하고 있는 추세여서 민관협력은 급속히 확장될 것으로 예상된다.

6) 흔히 오너십(ownership)을 국내에서는 주인의식이라고 번역하고, 일본에서는 '자조노력'이라고 번역하여 사 용하고 있으나 이러한 번역은 개발도상국의 주민들을 게으르고 의존적이며 자조적이지 못하고 주체적 의식 이 결여된 사람들로 규정하는 공여국의 편견과 태도가 깔려있는 오역임. 오너십은 개발의 주체와 주인이 개 발도상국의 주민들 자신이라는 것이고 발전권이 주민들에게 있다는 인권법적, 규범적인 개념으로서 '개발주 권'이라고 번역하는 것이 옳다.

7) 2002년 멕시코 몬테레이에서 열린 이 회의의 합의문서에서는 개발재원을 국내재원, 국제재원, 국제무역, 외 채탕감, 개발협력, 국제체제 개혁의 6 개 부문에서 동원하는 것으로 하였으며, 이를 위해 민간부문 발전과 민 관협력(PPP), 반부패, 거버넌스, 국제금융기구의 개혁, 항공권연대기금와 같은 새로운 개발재원, 외채탕감, $\mathrm{ODA}$ 증액, 남남협력과 무역촉진 등의 다각적 노력이 필요함. 그러나 글로벌 금융위기 등으로 인해 몬테레이 합의의 이행성과는 매우 저조함. 
부산 글로벌파트너십 선언에서도 개발도상국 발전을 위해서는 민간부문의 기여와 참여가 필수적임을 강조하였는데, 주목할 것은 공여국 정부와 민간기업의 파트너십 뿐 아니라 개도국 내에서 민간기업들이 개발에 참여할 수 있는 환경을 조성하고 민간부문을 활성화하는 것이 발전에 더욱 중요하다. 때문에 최근에는 개도국에서 사회적 기업이나 협동조합, 마을기업, 벤처기업을 포함하는 다양한 형태의 창업활동을 지원하는 방식의 개발협력이 확산되고 있는 것도 주목할 만하다.

\section{(4) 원조 투명성과 책무성 강화}

파리선언 이후 부산 글로벌 파트너십에서 새롭게 한층 강화된 정책이 개발협력의 책무성과 투명성 강화 노력이다. 이는 개발협력에 관한 정보를 국제적으로 합의된 공통 기준이나 IATI(International Aid Transparency Initiative) 데이터 보고기준에 따라 전자 공시하는 것을 권고하는 조치라고 할 수 있다. 원조의 투명성과 책무성 제고는 부패를 예방하고 민주적이고 참여적인 방식으로 개발협력을 수행하여 궁극적으로 개발효과성을 제고하기 위한 필수 조건이다. 따라서 많은 공여국들이 IATI에 가입하여 정보공개를 추진하고 있을 뿐 아니라 납세자들에게 적극적으로 개발협력의 정보와 성과를 알림으로서 국민의 지지기반을 강화하는 노력을 경주하고 있다. 원조의 투명성과 책무성 강화의 또 다른 이행방식은 개발협력에 대한 상호평가를 통해 개발 주체간의 상호 책무성을 강화하는 것이다. 개발협력을 공동으로 평가함으로써 개발협력의 수행과정과 제도, 예산, 성과 측면에서 문제점과 개선사항을 발견하고 원조의 효과성을 제고할 수 있다. 또한 시민사회와 지방정부, 의회 등 다양한 주체들이 지속적으로 모니터링과 평가과정에 참여하게 함으로써 개발효과를 높일 수 있으며, 평가결과를 모두 이해관계자들에게 공개함으로써 책무성을 제고하게 된다.

\section{II. 문화 ODA의 필요성과 현황}

\section{1. 문화 $\mathrm{ODA}$ 의 가치}

\section{(1) 문화를 통한 발전의 재구상}

발전이 무엇인가에 대한 많은 논의들이 지난 반세기 동안 지속되어 왔으며 후기 구조주의와 포스트모더니즘의 영향으로 탈발전(post-development) 담론이 유행하면서 개발과 원조 정책 담론의 해체 작업이 광범위하게 진행되었다.8) 이러한 결과로 경제와 기술, 물질중심주의에 대한

8) Ferguson, James.(1990), Anti-Politics Machine; Development, Depolitization and Bureaucratic power in Lesotho, Cambridge Univ. Press. 
성찰이 나타났으며 동시에 경제성장 일변도의 단선적 발전론에 대한 반성도 확산되어 인간중심 발전론과 자유로서의 발전(development as freedom) ${ }^{9}$ 과 같은 다양한 발전론이 등장하게 되었다.

개발협력에 있어서도 서구 중심의 자본제적 발전 경험을 비서구 사회에 그대로 이식하는 것은 상이한 역사와 문화, 환경을 지닌 개발도상국에게 진정한 발전과 자유, 가능성을 부여하기 보다는 종속과 의존을 심화시키고 문화를 파편화시키고 물질주의를 확산할 뿐이라는 반성도 대두되었다. ${ }^{10}$ 발전의 의미가 무엇인지, 무엇이 진정한 발전인지를 규정하는데 있어서도 특수한 환경과 조건에서 생존하고 있는 사람들의 문화가 가장 중요한 성찰적 가치를 제공한다고 볼 수 있다. 그래서 세네갈의 시인 생고르의 말대로 “문화는 발전의 본질이고 궁극 목적"(Culture is the be all and end all of development)인 것이다.

즉, 문화 없는 발전은 아무 의미가 없으며 자신들의 문화를 고려하지 않은 개발협력은 목적을 상실한 외부의 개입이 될 우려가 크다. 모든 식민주의와 제국주의, 강압적 세계화와 외부의 개발이 실패하거나 원주민들에게는 진보가 아니라 퇴보를 초래하고 커다란 혼란과 피해를 가져다주었으며 결국 그 사회의 생존 자체를 불가능하도록 한 이유도 문화 없는 개발이었기 때문이다. 유네스코의 문화발전 10년 보고서인 〈우리의 창조적 다양성〉에서도 인간적, 문화적 맥락과 결별한 개발은 영혼이 없는 성장일 뿐이라고 경고하고 있는 바, 문화는 발전과 개발협력의 목적을 규정하고 의미를 부여하는 자성의 거울이고 의미의 원천이며 맥락이라고 할 수 있다.

\section{(2) 경제적 가치에서 발전의 동력으로}

문화는 단지 경제발전을 위한 도구적 가치를 지니는 것이 아니라 발전의 동력이고 저수지이며 보편성을 부여하는 의미의 장치이다. 발전 문제는 역사적, 통시적 상대주의 관점에서 보아야 할 뿐 아니라 문화 상대주의적 가치에 의해 서로 다른 국가와 사회가 지니는 발전의 특수성을 인정하고 비교할 수 있다. 즉 모든 발전을 서구화, 근대화, 물질화, 기술주의에 의해 단선적으로 평가할 수 없으며 풍요한 소비사회가 발전의 동일한 보편적 목표도 아니다.

문화는 한 사회와 국가가 지닌 물질과 정신, 제도와 가치체계를 모두 포함하는 것이며 발전의 경로와 과정, 목적과 의미를 규정하는 것이기 때문에 문화를 단순히 경제적 가치와 수단으로 환원할 수 없다. 즉, 경제발전을 위해 문화가 함몰되어 도구화되어서는 곤란하며, 문화는 발전의 성격과 목적, 수단을 연결 짓고 자원을 동원하여 변화를 만드는 보이지 않는 동력이다. 지난 반세기 동안의 한국과 아프리카 등 다른 저개발국을 비교한 많은 연구 결과에서도 이들 간의 결정적 차이를 만드는 것은 경제도, 기술도, 환경도, 자원도 아닌 문화이다. 문화가 발전을 이루는 원동력이 되고 있으며 문화자본과 사회자본의 특성에 따라 발전의 성격과 속도, 경로가 결정되기도 한다. ${ }^{11}$

9) Sen, Amartya(1999), Development as Freedom, Oxford Univ. Press

10) 노르베르 호지의 〈오래된 미래〉, 슈마허의 〈작은 것이 아름답다〉 등.

11) 헌팅톤 외, 이종인 역(2000), 〈문화가 중요하다〉, 김영사. 
그러므로 문화 ODA란 단지 경제발전을 위한 문화지원 프로그램이 아니다. 문화 ODA가 문화 분야에 대한 개발협력 사업에 국한되는 것도 아니다. 오히려 문화 ODA는 개발도상국 주민의 자긍심과 전통을 존중하고 문화 상대주의적 관점을 견지함으로써 그 사회의 특수한 발전의 경로와 목적, 개발주권을 인정하고 주체적이고 다양한 발전과 사회변화가 가능하도록 지원하는 협력의 원칙과 접근 방법을 의미한다.

\section{(3) 포용적 발전을 위한 문화자산 활용}

최근 세계적으로 양극화와 빈부격차, 분쟁과 배제가 심화되면서 포용적 발전(inclusive development)이 중요한 정책 담론으로 대두되고 있는데 이는 발전과정과 발전의 성과가 소수에게 독점되지 않고 모두를 위한 발전(development for all)이 되어야 함을 의미한다. 포용적 발전은 소수자와 소수민족, 주변화 된 계층과 빈곤층 및 여성이 발전과정에 민주적으로 참여하고 발전의 혜택이 이들 모두에게 골고루 돌아가는 공정하고 공평한 것이어야 한다는 점을 강조하고 있다. 이러한 포용적 발전을 달성하기 위해서는 문화를 매개로 하는 문화적 접근과 문화자산을 활용하는 것이 필수적이다. 사회에서 배제된 계층과 소외된 자들은 토지 소유권, 개발권 등에서 차별과 배제의 대상이기도 하지만 무엇보다도 문화적으로 배제되고 차별받는 자들이기 때문에 이들에 대한 문화적 인정과 포용이 무엇보다도 우선되어야 한다. 배제에서 포용으로, 차별에서 평등으로, 소외에서 인정으로의 제도와 인식 변화가 필요하며 문화적 접근에 의해 이들을 발전과정의 주체이자 수혜자로 변화시킬 수 있다. 특히 배제되고 주변화 된 소수자들의 문화자산과 관습, 전통, 지역지식을 발굴하고 활용함으로써 이들을 효과적으로 발전과정에 참여할 수 있도록 할 수 있다. 언어, 종교, 의례, 축제, 숲과 거주지, 전통기술과 생계방식 등 문화자산과 지역지식(local knowledge)을 활용하는 문화적 접근에 의해 모두가 참여하고 모두에게 발전의 혜택이 배분되는 포용적 발전을 성취할 수 있는 것이다.

이러한 빈곤층과 주변화 된 계층 및 소수민족들에 대한 포용적 발전과 문화적 접근은 아래로부터의 참여에 의한 민주적, 참여적 개발과 자조 노력을 촉진하며 주민들의 개발 주권을 강화함으로써 궁극적으로 지속가능한 발전을 가능하게 한다. 외부의 개입 프로그램인 개발협력도 이러한 빈곤층의 문화자산 활용 방식에 의해 발전과정과 목적을 주민들을 통해 내재화, 주체화할 수 있으며 빈곤층과 문화적 소외계층의 역량강화와 문화권 확대를 통해 포용적 발전과 지속가능한 발전을 달성할 수 있다. 이것이 포용적 발전을 위해 문화 ODA가 필요한 근본 이유이다.

\section{(4) 생물 종 문화다양성과 지속가능발전의 축으로}

세계화와 자본주의의 고도화에 따른 기술, 물질주의의 확산은 전 지구적 환경위기를 초래하였고, 지구온난화와 급격한 기후변화는 생물 종 다양성과 문화 다양성의 위기를 불러오고 있다. 때문에 기후변화를 완화하고 이에 효과적으로 적응하고 대처하는 방법은 생물 종 다양성과 문화 다양성을 보호하는 것이며 지속가능 발전은 곧 이러한 전 지구적 환경위기와 개발위기에 대처하여 생물종과 
문화다양성을 지키려는 인류의 생존 전략이다. 생물 종 다양성과 문화 다양성은 인간과 환경을 분리할 수 없는 것처럼 상호불가분의 관계에 있다. 생물 종 다양성이 파괴되고 위협을 받는 것은 곧 문화 다양성이 파괴되는 것이며, 역으로 문화 다양성이 위험에 처하는 것은 곧 생물 종 다양성이 파괴되는 것과 같다.

문화는 지속가능 발전의 네 번째 축으로서 사회, 경제, 환경적 지속가능성에 추가되어야 하는 인류 공동의 생존 전략이다. ${ }^{12)}$ 사회적 지속가능성은 사회적 통합과 이동을 촉진하고 주변화 된 계층과 주민들의 권한을 강화하며 참여를 확대하고 민주적 제도발전을 이루는 것에 의해 사회정의를 구현하는 것이다. 반면에 환경적 지속가능성은 자연자원을 효과적으로 관리하고 생물 종 다양성을 보호하며, 지구 생태계의 수용능력을 고려한 발전에 의해 생태계의 균형을 지속하는 것이다. 또한 경제적 지속가능성은 균형성장과 공정한 무역에 의해 경제적 평등과 상호 협력을 촉진하고 자립 기반을 확대하는 것이다. 이에 비하여 문화적 지속가능성은 다양한 문화 정체성을 인정하고 존중하며, 유무형의 문화유산과 문화자산을 보호하고 지역문화와 지역지식을 활용하여 문화산업과 문화 다원주의를 확산하는 것이다. ${ }^{13)}$ 문화 $\mathrm{ODA}$ 는 궁극적으로 생물종과 문화 다양성을 촉진하고 지속가능 발전에 기여하기 위한 개발협력 노력이라고 할 수 있으며 특히 문화적 지속가능성을 확대하고자 하는 국제사회의 공동 노력이다.

\section{2. 국제사회의 문화 ODA에 대한 논의}

\section{(1) 유엔 및 유네스코의 문화와 발전 논의}

문화와 발전에 관한 국제사회의 논의는 1948 년에 유엔에서 제정된 세계인권선언 제 27 조 1 항의 "모든 인간은 공동체의 문화생활에 자유롭게 참여하고, 예술을 감상하며, 과학의 진보와 그 혜택을 향유할 권리를 지닌다"는 선언에서 비롯된다. 즉, 문화적 권리는 인간의 기본인권에 속하는 것으로 모든 발전은 이러한 인간의 문화권을 보장하고 확대하는 것이어야 한다는 원칙을 확인한 것이다. 이후 유엔은 1966년 '경제, 사회, 문화적 권리에 관한 국제협약'(ICESCR)과 시민, 정치적 권리에 관한 국제협약(ICCPR)을 통해 문화권을 구체적으로 규정한 바 있다.

유네스코는 1960 년 개발의 연대로부터 발전과 문화와의 불가분의 관계를 확인하였으며 문화발전과 문화정책, 국제문화협력에서 문화 다양성과 문화권을 보호하고 신장하는 노력을 경주하였다. 예를 들면 1966년 제정된 유네스코의 국제문화협력원칙선언(Declaration of the Principle of International Cultural Cooperation)에서는 "모든 인간은 자신의 문화를 발전시킬 권리와 의무를 지닌다.” 라고 규정하였다. 또한 1970 년에 베네치아에서 개최된 ‘문화정책에 관한 정부간회의'에서는

12) Hawkes, Jon(2001), The Fourth Pillar of Sustainablity: Culture's Essential Role in Public Planning. (www. culturaldevelopment.net.au)

13) Nurse, Keith(2006), "Culture as the Fourth Pillar of Sustainable Development", Commonwealth Secretariat, UK. 
문화발전이라는 개념을 논의하면서 발전의 문화적 측면을 집중적으로 다루고 국제개발원조가 문화 진흥과 정신적, 물질적 문화유산의 보존을 위해 확장되어야 한다고 주장하였다. 이 회의 보고서에서 문화 발전은 사회, 경제적 발전의 필수요소이고 사회와 경제발전을 위해서는 국가 정체성을 우선 확립하여야 한다고 하였다. 이점은 개발도상국과 신생독립국들에게는 매우 중요한 문제였으며, 국가와 문화 정체성의 확립은 민족국가의 통합과 경제사회발전의 기초가 되었다.

1982년 멕시코시티에서 개최된 유네스코 세계문화정책회의에서도 균형 잡힌 발전을 위해 개발전략에 문화적 요소를 포함시켜야 한다고 하였으며, 개발 경제발전을 넘어서는 복합적이고 전 지구적이며 다차원적인 과정으로서 공동체의 모든 에너지와 생활양식을 포괄하면서 구성원들이 공동체의 이익을 지지하고 공유하도록 하는 과정이라고 보았다. ${ }^{14}$ 1988년부터 1997 년까지 10 년 동안 추진되었던 유네스코 세계문화발전 10 개년 사업의 결과로 세계문화발전위원회가 만든 보고서 '우리의 창조적 다양성'(Our Creative Diversity)은 문화와 발전에 관한 핵심 원칙과 방법을 제시하였다. 이 보고서에서는 “인간적, 문화적 맥락과 결별한 개발은 영혼이 없는 성장이다"라고 말하고 있으며 새롭고 다양한 형태의 다원주의를 통해 다민족, 다문화 사회를 만드는 방법들을 제시하고 있다. 특히 창의성 촉진, 디지털 격차 해소, 양성평등 관점, 청년의 역할과 환경 관리의 문화적 측면을 강조하였다.

2001년 세계문화다양성 선언은 문화다양성이 발전의 근간이고 발전의 중요 요소라고 하고 있다. 이 선언은 법적 구속력이 없으므로 이후 2005년 '문화적 표현의 다양성 보호와 증진을 위한 협약'으로 발전하였으며, 이 협약은 문화적 자산과 서비스가 정체성, 가치, 의미의 담지자로서 단순한 소비재와 다르다는 것을 인식하도록 하였고 국제협력을 통해 상시적으로 문화 다양성과 지속가능한 발전을 증진하도록 하였다. 이후에도 유네스코는 2008년 세계 언어의 해, 2009년 문화 다양성과 문화간 대화 보고서 발간, 2010 년 문화간 화해의 해 등을 통해 문화와 발전의 불가분성을 강조하고 문화를 통해 발전을 재구상하는 노력을 경주하였다.

한편 UNDP의 2004년 〈인간개발보고서〉에서는 오늘날 다양한 세계의 문화적 자유를 주제로 다루면서 문화 다양성의 관리가 우리 시대의 중요한 과제 중 하나가 되었음을 강조하였다. UNDP 는 이 보고서를 통해 빈곤퇴치와 $\mathrm{MDG}$ 달성을 위해서는 문화적으로 다양하고 포용적인 사회를 어떻게 만들어야 하는가를 고민해야 한다고 하였으며, 문화적 자유가 개발전략에 반영되어야 한다고 주장하였다. 또한 2009년의 〈인간개발보고서〉에서도 국제이주를 다루면서 문화적 정체성과 다양성을 옹호하는 정책이 중요함을 지적하였으며 인간의 선택권을 확장하고 소수집단을 문화적으로 배제하지 않는 것이 중요함을 강조하였다.

이러한 논의를 토대로 2010년부터 2011년, 2012년 연속적으로 유엔총회는 문화와 발전에 관한 의제를 상정하여 총희 결의안을 채택하였다. 이 유엔 결의안에서는 지속가능 발전과 국가 개발목표, $\mathrm{MDG}$ 를 달성하기 위해 문화의 기여가 중요함을 강조하고 있으며, 문화가 주민들의 혁신과 창의 역량을 개발하는데 결정적으로 중요하다는 것을 인식해야 한다고 결의한 바 있다. 유네스코는 제 66

14) Marana, M(2010), Culture and Development: Evolution and Prospects(유네스코 번역)에서 재인용. 
차 유엔총회에 제출한 문화와 발전에 관한 보고서를 통해 보다 포용적이고 보다 평등하며 지속가능한 발전을 위해서 '문화와 발전에 관한 유엔회의'를 개최해야 한다고 제안하였으며 유엔은 공식적으로 이 회의의 타당성을 검토하기로 하였다.

\section{(2) 선진 공여국들의 문화 ODA 정책과 프로그램}

선진 공여국들은 개발협력 정책문서와 국별협력 전략을 통해 주요 파트너 국가와의 다양한 문화협력과 문화 $\mathrm{ODA}$ 를 확대 추진하고 있으며 문화와 발전과의 연계성과 상호보완성, 통합성을 강조하고 있다. 주목할 것은 문화 $\mathrm{ODA}$ 를 강조하는 국가들은 거의 구식민지와의 역사적, 문화적, 언어적 연대가 강한 선진국가들(프랑스, 스페인, 영국 등)이거나 이슬람 지역에 대한 미국의 원조 프로그램과 같이 갈등과 분쟁, 문화적 차이 등으로 접근이 어려운 지역에 대한 문화적 프로그램을 중시하는 사례들이 많다는 점이다. 이는 문화 ODA가 구식민지 관리와 문화적 유대를 통해 국제사회에서의 상호지지 기반 마련의 수단으로 활용되고 있음을 확인할 수 있다. 특히 문화 ODA 가 문화 차이와 갈등이 큰 지역에서 이질적 문화 간 상호이해와 소통을 증진하고 평화의 문화를 정착시키는데 크게 기여하고 있는 것을 알 수 있다.

예를 들면 스페인 국제개발협력청(AECID)은 문화 관리를 위한 인적자원 양성과 문화와 발전에 집중하는 프로그램을 강조해 왔다. 즉, 발전에 기여하는 문화의 정치적 차원과 경제적 차원의 사업을 추진하였으며, 교육과 문화와 상호 보완적 관계를 강조하는 사업도 지속 추진 중이다. 스페인은 발전을 위한 문화유산의 지속가능한 관리와 발전에 영향을 미치는 커뮤니케이션과 언어 전통, 문화적 권리에 대한 인식증진 프로그램 등을 실시하고 있다. 프랑스 개발청(AFD)은 지식과 문화의 교류 증진을 개발협력의 5 대 비전 중 하나로 채택하고 있으며, 문화와 발전에 대한 다양한 연구사업을 지원하고 있다. 특히 불어 사용 지역 개발도상국들에 대한 집중적인 교육과 언어, 문화유산 관리 지원을 통해 전통적인 식민지 유대를 지속하고 강화하려고 하고 있다. 영국의 국제개발부(DFID) 는 문화와 발전을 위한 창조적 교류를 중시하고 있으며 문화가 국제개발협력의 중요한 영역으로 자리 잡았다. 문화는 발전에 내재한 것(culture is embedded in development) 것이라는 인식하에 경제성장, 문화 다양성, 발전의 문화적 접근, 문화 표현, 문화 정체성, 사회변화를 위한 예술, 인권과 문화권 분야 등을 집중 지원하고 있다. 특별히 영연방 재단(Commonwealth Foundation)은 문화 우선사업(Putting Culture First)을 별도로 수행하고 있으며 영연방 국가들 중 개발도상국들에 대한 다양한 문화사업을 지원하고 있다. 미국은 이집트, 예멘, 레바논, 요르단, 모로코, 이라크 등 중동 북아프리카 지역(MENA)에서 문화와 발전 지역파트너십 프로그램을 집중 실시하고 있다. 이것은 이 지역의 특수한 개발경험과 지역지식을 발굴, 지원, 공유하는 것으로 디지털 도서관을 구축하고 연례 파트너십 포럼을 개최하며 특히 청년과 시민사회가 많이 참여하도록 함으로써 문화를 통한 연대와 협력을 강화하고자 하는 시도이다.

국제기구와 국제금융기구들도 문화와 발전에 관한 다양한 협력사업을 추진하고 있는데, 유엔 밀레니엄기금(MDG Fund)을 50개국에서 130여개의 공동사업을 통해 $\mathrm{NGO}$ 와 민간기업, 시민사회 등이 주요 파트너가 되는 문화협력 사업을 추진 중이다. 유네스코는 문화발전 지표사업을 통해 
경제, 교육, 문화유산, 커뮤니케이션, 거버넌스, 사회, 성평등 분야에서 문화지표를 개발하였다. 또한 '문화 다양성 렌즈' 사업을 통해 주요 국제기구와 개발도상국의 개발정책과 사업을 문화적 관점에서 검토할 수 있도록 하였다. 세계은행과 지역개발은행들도 도시개발과 사회개발, 지속가능한 관광과 지역경제발전 프로그램에 문화를 접목시켜 지원하고 있으며 세계은행이 투자한 개발사업 중 문화적 차원에서 고려한 사업들이 40 억 달러에 달해 문화분야 지원이 지난 10 여 년 동안 현저히 증가하는 추세이다.

이처럼 국제기구와 선진 공여국들의 사례에서 보듯이 문화분야의 우선 협력사업은 문화유산과 전통지식 분야, 문화산업과 문화창업(기업가정신) 분야로 대별될 수 있다. 문화유산과 전통지식은 문화유산 보호에서 지역사회의 참여, 문화와 자연유산 관리능력 배양, 문화유산 관리를 위한 정부와 시민사회의 협력 촉진, 자원관리와 지역 거버넌스 능력 배양, 전통지식 기록과 문화가치 보존사업, 기초교육에서 토착 지식과 전통가치 전승, 토착언어 기록과 교과과정 통합 등이다. 문화산업과 창업 (기업가 정신) 분야는 문화 창업 교육훈련과 능력배양, 경제 다각화와 문화산업 투자 촉진, 관광, 교육, 지적소유권 분야에서 정부와 문화산업과의 협력 강화, 지적소유권 보호와 관리, 문화상품과 서비스, 권리 옹호를 위한 제도적 능력 구축, 자본과 신용대출 접근성 개선 등이다.

이상에서 살펴 본 바와 같이 문화와 발전에 대한 국제사회의 많은 논의에도 불구하고 문화 ODA 는 환경, 여성, 인권 등과 같이 개발협력의 범분야로서 아직 주류화 되지 못하고 있으며 제한적 의미에서 문화분야의 협력 사업으로만 조금씩 확대되고 있는 추세이다. "문화는 어머니고 제도는 그 자식”이라는 말과 같이 제도적 역량 구축과 제도 변화를 가능케 하는 것은 문화이다. 또한 문화의 토대 변화 없이는 사회변화도 기술과 경제 발전도 내재화되기 어렵다. 문화 ODA는 문화분야에 대한 지원으로서 의미보다도 문화적 자유와 지적, 문화적 창의성이 발전에 결정적으로 중요하다는 인식을 확산하고 이것이 가능하도록 하는 제도적 여건과 환경을 만드는 것이다. 문화 다양성과 지속가능발전 및 포용적 발전을 가능케 하는 것은 문화를 통한 개발협력이고 문화는 범 분야 ODA와 개발협력의 기본 원칙으로 주류화 되어야 한다.

\section{III. 우리나라 문화 ODA 추진과제}

\section{1. 우리나라 문화 ODA 현황}

우리나라의 ODA가 급속히 증가하고 있고 담론과 정책 수준에서 많은 발전이 있었지만 아직까지 문화와 발전에 대한 본격적인 논의도 문제의식도 없다. 2012년부터 유네스코한국위원회와 문화관광체육부가 추진하고 있는 문화와 발전 라운드테이블 및 연구 성과가 거의 유일한 것이다. 또한 우리나라가 추진하고 있는 소위 '한국형 ODA' 라는 159 개의 모델 가운데도 문화 분야 ODA는 '역사문화도시 조성계획' 하나 밖에 없다. 이는 우리나라의 급속한 경제개발과 압축적 근대화과정에서 
경제와 기술, 교육과 보건과 같은 분야에 비하여 문화가 적절히, 그리고 충분하게 고려되지 못한 이유가 크겠지만 국제사회에서도 문화 ODA 논의가 아직도 실질적 프로그램 개발과 정책논의로 발전하지 못했기 때문이기도 하다.

한국형 개발경험이라는 말이 문화와 환경을 적절히 고려하지 못한 경제와 물질, 기술중심의 개발과 관주도의 개발국가 모델로 상정되는 이유도 우리나라의 개발과정에서 문화적 전통과 토양이 파괴되고 무시되었던 사례가 많기 때문이다. 일제하의 식민지 개발이 그러하였으며 해방이후 민족국가 수립과 분단, 전후복구와 근대화과정이 그러하였다. 특히 경제개발 과정에서 농촌과 기층문화는 전근대적 유산으로 치부되어 철저히 희생되었으며, 새마을운동은 농촌 근대화라는 이름으로 지방과 지역문화를 파괴하였다. 급속한 도시화와 개발의 열풍으로 공동체는 사라졌으며 의식주와 모든 생활방식의 서구화와 천민 자본화가 진행되었다. 1988년 올림픽 이후 비로소 우리나라의 압축적 성장과 개발경험에 대한 성찰이 시작되었으며 문화와 환경, 그리고 삶의 질이 다른 어떤 것과도 치환될 수 없는 소중한 가치라는 것을 깨닫기 시작하였다.

기존 연구에서는 우리나라의 문화 ODA를 '문화인지 ODA'와 문화분야 ODA'로 편의상 구분하고 있다(한국문화정책개발원 2010, 강주홍 2012). 전자는 문화에 대한 내포적 해석으로서 모든 $\mathrm{ODA}$ 사업이 개발도상국 주민의 감성과 자긍심, 고유문화를 존중하면서 발전을 추구해야 한다는 가치규범적 측면을 말하는 반면에 후자는 협의적 관점으로서 예술, 관광, 스포츠 등 문화영역을 활용한 ODA 사업을 말한다. 이러한 구분에 의해 문화 ODA란 주로 문화분야 ODA를 지칭하는 것으로 통용되고 있으며, 이를 개발원조위원회(DAC)의 원조목적별 통계분류 지침에 의해 '경제하부구조 및 서비스' 부문의 '기타 사회인프라 및 서비스'의 하위 영역인 '문화 및 레크레이션 분야'로 구분하고 있다. 이에 의하면 문화 ODA는 1) 음악, 영상, 미디어, 스포츠 관련 장비지원, 2) 극장, 문화센터, 박물관, 미술관, 기록물보관소 등의 시설지원, 3) 예술, 스포츠, 언어문학, 미디어, 문화유산 보호 등 역량개발 프로그램 지원으로 구분하고 있다. (강주홍 2012에서 재인용).

우선 우리나라의 '문화인지 ODA'는 매우 초보적 수준에서 언급되고 있는 정도이며 그것도 파트너 국가의 문화를 고려하는 것이 아닌 한국의 문화를 전파한다는 자문화중심주의(ethnocentric) 수준에서 논의되고 있는 실정이다. 예를 들면 '국제개발협력 선진화 전략'에서 "특유의 한국적 감성 또는 미를 가미하거나 진정성을 느낄 수 있는 감동 사례를 정리하여 ODA 부가가치 제고에 활용" 한다는 식이다. 다만 국별협력전략(country partnership strategy) 수립 가이드라인에서는 국가 개황에 인구, 종교, 문화, 교육, 보건, 도시화, 자연재해 취약성 등 사회현황을 조사하고 인간개발지수 (HDI) 분석을 요구하는 등의 수준에서 협력국의 문화를 고려하고 있다. $\mathrm{EDCF}$ 의 환경 세이프가드에도 $\mathrm{ODA}$ 추진 시에 문화적 가치의 존중과 문화 다양성의 보존을 포함시키고 있는 정도이다.

문화분야 ODA 사업도 아직 매우 미미한 수준에서 추진되고 있다. 문화체육부가 문화 ODA를 10 대 핵심 추진과제로 추진하고 있지만 '역사문화도시조성계획' 이외에는 한국형 ODA 모델에 포함된 협력사업 사례가 아직 없으며, 대부분의 예산은 유네스코와 세계관광기구(WTO), 세계지적재산권기구 (WIPO) 등을 통한 국제기구 협력사업이 주종을 이룬다. 문화재청을 통해서는 문화유산의 발굴, 
보존, 관리를 지원하기 위한 협력사업을 추진하고 있으며 베트남, 몽골, 스리랑카, 라오스, 부탄, 피지 등에서 문화유산 보존기술과 무형유산 보호제도 구축, 세계기록유산 등재지원 등의 사업을 수행한 바 있다.

한국국제협력단(KOICA)의 문화분야 ODA사업도 교육, 보건, 공공행정, 농립수산, 산업에너지, 범분야, 기후변화대응 등 7대 중점협력 분야에 포함되고 있지 못하다. 때문에 문화 ODA에 대한 정책이나 전략, 협력 가이드라인은 없다. 때문에 연관성이 없는 개별사업들이 나열되고 있을 뿐이며 역사자료 전산화사업(이집트, 콜롬비아), 지역관광개발사업(페루, 카자흐스탄, 우즈베키스탄), 문화도시 마스터플랜사업(네팔, 베트남) 등을 추진하였다. 이처럼 우리나라의 문화 ODA는 기본 전략도 정책도 가이드라인도 없는 실정이며 부분적인 소수의 개별사업들만이 코이카나 문화재청, 국제기구와의 사업으로 추진되고 있는 상황이다.

\section{2. 우리나라 문화 ODA 추진과제}

\section{(1) 문화와 발전 의제와 정책개발}

문화 ODA 논의를 위해서는 문화와 발전에 대한 포괄적인 의제개발과 의제설정 노력이 우선적으로 필요하다. 특히 우리나라의 압축적 성장과 개발경험, 세계화와 초국가적 경험에서 문화와 발전에 대한 유의미한 사례, 성공과 실패의 경험, 국가적 수준과 지역 수준에서의 문화와 개발 경험 등을 다방면으로 도출하는 기본연구가 절실히 필요하다. 이는 유엔과 유네스코를 중심으로 전개되고 있는 '문화와 발전에 관한 세계총회'의 개최를 고려할 때도 매우 긴요한 작업이 될 것이다.

이러한 한국의 개발경험 연구를 토대로 최빈국과 개발도상국의 발전 과정에서 토착지식과 문화전통, 문화유산, 정체성, 관광산업과 창조산업이 지니는 무한한 가능성에 주목하는 연구가 이루어져야 한다. 지금까지 창조산업과 문화발전에 대한 연구가 주로 영미의 선진국들을 대상으로 진행되었다면 이제는 신생독립국과 분쟁국, 최빈국과 개발도상국에 있어서 문화가 국가통합과 사회발전, 포용적이고 지속가능한 발전의 토대 형성에 얼마나 중요한가를 입증하는 사례연구를 수행함으로써 문화와 발전 논의를 포괄적으로 진척시켜야 한다. 이러한 기초 지역연구를 토대로 할 때 문화 ODA에 대한 기본정책과 중장기 전략, 국별협력전략을 마련할 수 있으며, 나아가 문화를 $\mathrm{ODA}$ 의 범 분야 이슈와 접근방법으로 확산시킬 수도 있을 것이다.

\section{(2) 지역지식 축적과 지역전문가 육성}

문화 ODA는 협력국의 지역문화와 지역지식을 기반으로 수행되는 것이기 때문에 우리나라의 일천하고 미진한 지역지식 수준과 세계 각 지역의 전문가 부족이 문화 ODA에 가장 큰 장애 요인이다. 우리나라는 아프리카나 중동, 남미, 오세아니아, 동남아나 서아시아 지역에 대한 지역전문가가 매우 소수이고 지역지식의 축적 정도가 미진하기 때문에 지역에 맞는 문화 $\mathrm{ODA}$ 를 설계하는데 어려움이 
많다. 지역지식(local knowledge) 없이는 항해와 농경이 불가능한 것과 같이 정치도 법도 문화도 모두 지역지식이 있을 때만 올바로 작동한다. 더구나 국제개발이라는 응용 실천분야는 지역지식 없이는 제대로 작동할 수 없다(이태주 2011). 또한 지역전문가는 "특정 지역의 현지어와 현지문화를 익혀 현지인과 자유롭게 소통할 수 있고 특정 분야의 지역지식을 체계적으로 지니고 있는 자"이다 (이태주 위 논문). 우리나라의 ODA는 양적 질적으로 크게 성장하고 있지만 이러한 지역지식과 지역전문가의 층이 매우 일천하여 장기적인 국제개발 개선 노력에 많은 어려움이 있다. 문화 ODA 는 가장 정교하고 지속가능한 협력전략이며 현지 사정에 밝은 지역전문가들을 필요로 한다. 문화 $\mathrm{ODA}$ 추진과제는 곧 지역지식을 어떻게 축적하고 활용할 것인가의 문제이고, 지역전문가를 어떻게 양성하여 국제개발에 활용할 것인가의 문제이다. 장기 파견 해외봉사단이나 청년인턴, 각종 전문가 파견제도가 지역전문가 양성 프로그램과 연계되어야 하는 이유도 여기에 있다. 식민지 지배경험과 유산이 없는 우리나라가 지역지식을 축적하고 지역전문가를 키워내기 위해 체계적이고 전략적인 노력을 경주할 때이다. 미국의 평화봉사단에 대한 장학제도와 지역전문가 육성, 활용 경험을 참고로 할만하다.

\section{(3) 문화 ODA 모델발굴과 확산 주도}

2014년도 정부의 ODA 예산 가운데 주목할 것은 문화체육관광부 소관으로 109 억원의 예산이 배정되어 있으며 정부가 문화분야 $\mathrm{ODA}$ 를 적극 발굴 추진하고 있다는 점이다. 특히 개발도상국 관광 발전 지원을 위해 민관협력사업( $\mathrm{PPP})$ 을 추진할 계획이고, 해외문화 예술 봉사단도 파견할 계획이다. 최근 캄보디아의 앙코르왓트 유적 중 프레야 피투 사원을 복원하는 사업을 확정하고 사전타당성 조사단이 파견될 예정이며, 미얀마의 버간 유적지를 세계문화유산에 등재시키는 작업을 한국이 적극 지원하고 있는 것도 주목할 만하다. 또한 베트남의 고산지역인 라오까이 지방에서 생태관광을 개발하기 위한 마스터플랜 작업도 추진 중이다.

문제는 문화 $\mathrm{ODA}$ 를 추진하는 기본 방향과 전략이 부재하여 한류를 수출하듯이 한국 문화를 전파하고 수출하는 수단으로 ODA를 활용할 위험성이 많다는 것이다. 한국형 ODA 모델로서가 아니라 협력국 실정에 맞는 '효과적이고 지속가능한' 다양한 문화 ODA 모델을 발굴하고 확산하는 것이 중요하다. '역사문화도시조성계획'은 빈곤국과 개발도상국에서 매우 중요한 의미를 지니며 후에나 룸비니의 사례에서 보듯이 마스터플랜 수립부터 실제 도시 재생과 개발에 필요한 재원과 기술, 노하우를 제공하는 것이 매우 중요하다. 종교분쟁과 종족분쟁 등으로 평화가 위협받고 있으며 민족통합이 이루어 지지 못한 많은 신생국과 개발도상국에게 있어서 통합을 위한 문화 ODA도 매우 중요하다. 통합을 위한 문화 $\mathrm{ODA}$ 는 일국의 문화정책 전반에 대한 자문과 정책수립, 문화예산과 시설, 프로그램에 대한 지원을 포괄하는 지원이 되어야 효과가 있다. 언어, 예술, 문화유산, 관광, 미디어, 창조산업을 포괄하는 국가문화발전 계획을 수립하고 이에 필요한 패키지형 지원을 함으로써 문화 $\mathrm{ODA}$ 가 국가통합과 정체성 확립, 자긍심과 자존감 향상을 통해 문화산업 발전에 이르는 단계적 발전전략 이행을 가능하게 한다. 이러한 포괄적 지원을 할 수 있는 문화 ODA 중점대상국을 정할 필요가 있으며 동티모르, 에티오피아, 미얀마, 과테말라 등이 우선 고려할만한 국가들이다. 
우리나라의 ICT 기술은 문화 ODA를 확산할 수 있는 매우 유용한 수단이고 전략이다. ICT4D(ICT for Development)는 다른 섹터 뿐 아니라 교육과 문화 분야에서 매우 유효하며 특히 지역지식의 축적과 활용, 창조산업의 육성과 문화유산 보호 및 관리, 관광산업, 문화와 예술의 향유를 통한 삶의 질 향상이라는 측면에서도 ICT는 문화 ODA에서 빼놓을 수 없는 수단이다. ICT를 활용한 문화유산 보존과 관리, 문화교육과 문화유산의 활용방안, 문화산업과 지역경제 활성화, 지역재생을 위한 협력전략을 한국 $\mathrm{ODA}$ 의 중점 전략으로 구체화할 필요가 있다. 


\section{〈참고문헌〉}

강주홍 2012.「한국 문화 ODA 현황과 전망」, 유네스코한국위원회, 2012 유네스코 문화와 발전 라운드테이블 $\lrcorner p p$ 76-84.

문화체육관광부, 『2012. 문화와 발전: Post-MDGs 시대의 과제와 전망』.

$\mathrm{UNESCO}$ 세계보고서(유네스코한국위원회 역), 2009.『문화다양성과 문화간 대화』.

유네스코한국위원회, 2008. 『유네스코와 문화다양성』.

유네스코한국위원회, 2012.『문화와 발전 라운드테이블』

이태주, 2011. 「국제개발협력 전문가양성 프로그램과 인류학적 지역지식의 접목」,

『직업능력개발연구』14권 1호. pp. 173-194.

임소진, 2013. 「Post-2015 개발 프레임워크와 UN 고위급패널보고서」『정 책과 이슈』10

호, $\mathrm{KOICA}$.

임소진, 2013. 「모두를 위한 품위있는 삶-Post-2015 개발의제를 위한 유엔사무총장 보고서」『정책과 이슈』12호, KOICA.

한국문화화관광연구원, 2010『문화분야 공적개발원조 사업개발 연구』.

헌팅톤 외(이종인 역), 2001『문화가 중요하다』. 김영사

Ferguson, James. 1990. Anti-Politics Machine; Development, Depolitization and Bureaucratic power in Lesotho, Cambridge Univ. Press.

Hawkes, Jon, 2001. "The Fourth Pillar of Sustainablity: Culture's Essential Role in Public Planning"(www.culturaldevelopment.net.au)

Halper, Stefan 2010, The Beijing Consensus, Basic Books:New York.

Marana, M., 2010. Culture and Development: Evolution and Prospects.

Nurse, Keith, 2006. "Culture as the Fourth Pillar of Sustainable Development", Commonwealth Secretariat, UK.

OECD, 2011. How's Life?: Measuring Well-being, OECD Publishing.

Sen, Amartya, 1999. Development as Freedom, Oxford Univ. Press

Stiglitz, J.E., Sen, A.\& Fitoussi, J-P., 2010. Mismeasuring Our Lives: Why GDP Doesn't Add Up, The New Press. 
UN, 2013a. A New Global Partnership: Eradicate Poverty and Transform Economies Through Sustainable Development, The Report of the High-level Panel of Eminent Persons on the Post-2015 Development Agenda, United Nations.

UN, 2013b. A Life of Dignity for All: Accelerating Progress towards the Millenium Development Goals and Advancing the United Nations Development Agenda Beyond 2015. General Assembly A/68/202. New York, United Nations.

\begin{tabular}{c} 
제 II장 \\
제III장 \\
\hline 섹 \\
터 \\
제 $\mathrm{I}$ 장
\end{tabular}

